\title{
Historical Background on the Study of Fibromyalgia Syndrome
}

\author{
Created by: Carmen M Galvez-sánchez ${ }^{1}$, Gustavo Reyes Del Paso ${ }^{2}$ \\ 1, University of Jaén; cgalvez@ujaen.es \\ 2, University of Jaén; greyes@ujaen.es
}

Version received: 17 June 2020

check for

updates

Pain has a multidimensional nature in which three dimensions are usually differentiated: the sensorydiscriminative, the emotional-affective and the cognitive-evaluative. Based on the duration, it is possible to distinguish between acute pain, when it is present for a period lower than 6 months; or chronic pain, if pain is present more than 6 months. Fibromyalgia Syndrome is a complex chronic pain disorder in which widespread and persistent musculoskeletal pain is accompanied by different symptoms such as fatigue, insomnia, morning stiffness, depression, anxiety and cognitive impairments. Fibromyalgia began to be studied from the 16th century and it received different names during its historical development. The main landmarks in the development of fibromyalgia term include -among others- when the French physician Guillaume de Baillou in 1642 provided the first description of the disease using the term "muscular rheumatism". The British neurologist W.R. Gowers in 1904 coined the term "fibrositis" in an article on lumbago. In 1944, F. Elliot suggested that the pain experimented by fibromyalgia patients might involve the spinal cord and thalamus. In 1968, E.F. Traut stated the first near-modern description of fibromyalgia with systemic features. In 1976, the term fibromyalgia was coined by P.K. Hench as a form of non-articular rheumatism based on the absence of specific inflammatory damage. In 1977, H.A. Smythe and H. Moldofsky continued the work of P.K. Hench and proposed the first measure for evaluating fibromyalgia. Nevertheless, it was not until 1981 that the medical community accepted this disease under the term "fibrositis" or "fibromyalgia" thanks to the work of Yunus et al. The distinction between primary and secondary fibromyalgia disappeared sometime later. During the 1980s, different authors suggested other formal and ad-hoc criteria sets. In 1987, the American Medical Association accepted fibromyalgia as a real disease. Shortly thereafter and as a result of this recognition, the American College of Rheumatology (ACR) created a committee to establish the diagnostic criteria for this disorder. The first official diagnostic criteria were proposed in 1990 by the ACR. In 1994, fibromyalgia was also recognized by the International Association for the Study of Pain. During the 1990s, there was an increase in fibromyalgia research. In 2010, the ACR proposed a new version of the diagnostic criteria based exclusively on the use of the Widespread Pain Index and the Symptom Severity Scale. In addition, other two subsequent diagnostic proposals were performed. In 2011, Wolfe et al. revised and modified the 2010 ACR diagnostic criteria to facilitate its use in epidemiological or community studies, but not for self-diagnosis in the clinical context. In 2016, ACR criteria were proposed to combine the 2010 and 2011 ACR criteria into a single set to overcome the previous limitations. Definitely, fibromyalgia involves high personal, family and financial costs. Fibromyalgia also implies high economic costs for the socio-health system. Fibromyalgia notably reduces perceived functioning in physical, psychological, and social spheres, and has a negative impact on personal relationships, parenting, work, daily activities, mental health and social relationships.

Pain has been defined by the International Association for the Study of Pain (IASP) as "an unpleasant sensory and emotional experience, associated with actual or potential tissue damage, or described in terms of such damage", thus including a subjective component. Pain has a multidimensional nature in which three dimensions are usually differentiated: the sensory-discriminative, the emotional-affective and the cognitive-evaluative[1] (See Figure 1). Additionally, pain can be classified according to different aspects, such as duration, cause, or anatomical location; among others criteria. Based on the duration, it 
is possible to distinguish between acute pain, when it is present for a period lower than 6 months; or chronic pain, if pain is present more than 6 months. ${ }^{[1]}$ Moreover, chronic pain is a serious health problem, which has a high comorbidity with other physical and emotional diseases such as anxiety, depression, insomnia and cognitive alterations. $\left.{ }^{[2]}\right]$

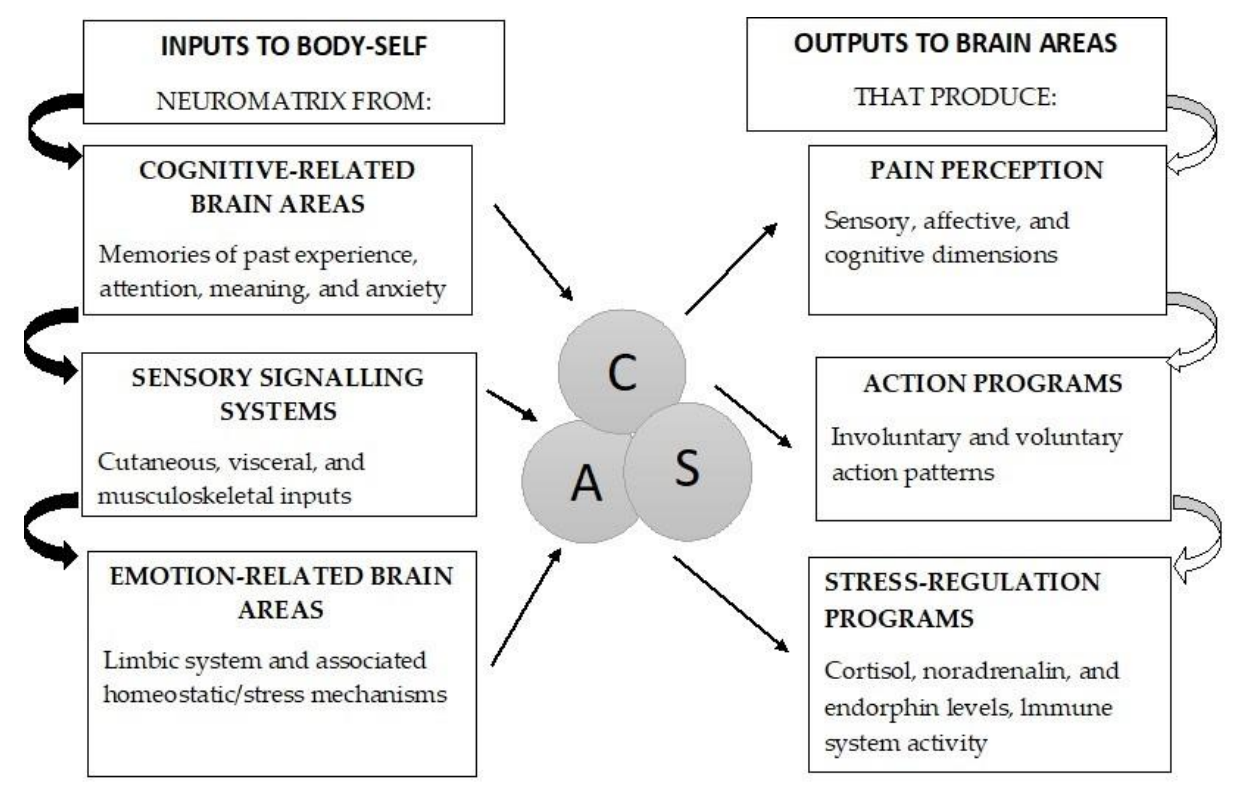

Figure 1. Neuromatrix of Pain: Sensory (S), Affective (A), and Cognitive (C) dimensions. Note: Adapted from Melzack. ${ }^{[3]}$

Fibromyalgia Syndrome is a complex chronic pain disorder that affects between 0.25 and $5 \%$ of the world population, being more frequent in women than in men, ${ }^{[4]}$ although this gender prevalence is being revised due to possible gender biases in epidemiological data. []][ㅌ] The widespread and persistent musculoskeletal pain is accompanied in fibromyalgia by different symptoms such as fatigue, insomnia, morning stiffness, depression, anxiety and cognitive impairments (i.e., deficits in attention, memory, concentration, processing speed).[] [요 $[\underline{9}][\underline{10}][\underline{11}]$ A high comorbidity has been observed between fibromyalgia and Rheumatoid Arthritis, ${ }^{[12]}$ Systemic Lupus Erimatosus, ${ }^{[13]}$ Ankylosing Spondylitis, $\underline{14]}$ and Chronic Migraine. ${ }^{[15]}$ Furthermore, fibromyalgia is also associated with emotional comorbidities such as anxiety and depression. $[\underline{4}][\underline{16}]$

The origin of the term "fibromyalgia" comes from the Latin "fibro", which means fibrous tissue; from the Greek "mio", which means muscle and "algia", pain. Fibromyalgia began to be studied from the 16th century and it received different names during its historical development such as muscular rheumatism, fibrositis, fibromyopathy, psychogenic rheumatism, interstitial myofibrositis, myasthenia, or

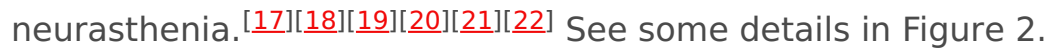

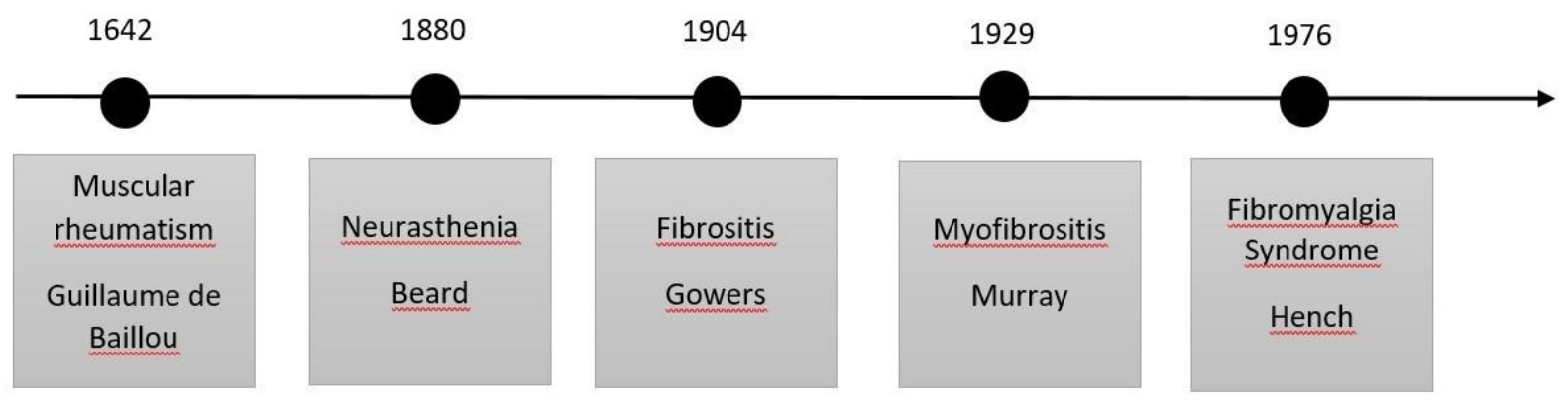


Figure 2. Main landmarks in the development of Fibromyalgia term.

The French physician Guillaume de Baillou in 1642 seem to be the first person who provided a description of the disease using the term "muscular rheumatism". [23] Baillou published this idea in his book "Liber de rheumatismo et pleuritide dorsali" and he commented that rheumatism was a type of fluid vessel disease, in which malignant humors flowed from the inside to the outside of the body, to be finally accumulated in the extremities and joints. $\underline{[23]}$

In 1750, the British physician R. Manningham published the paper "Symptoms, Nature, Causes, and Cure of Low-grade Fever or Fever: Commonly Called Nervous or Hysterical Fever; Spirit Fever; Vapors, Hiccups, or Spleen" $\left.{ }^{24}\right]$ and made different descriptions that might correspond to fibromyalgia. $\underline{25]}$

In 1843, the German anatomist R. Froriep described the concept of "tender points" in his treatise on pathology and therapy of rheumatisms and proposed an association between rheumatism and painful points of rigid muscles. $\left.{ }^{[26]}\right]$

In 1880, G.M. Beard, a neurologist from the United States, mentioned the term neurasthenia/myelasthenia to conceptualize a widespread pain (accompanied by fatigue and psychologic disturbance). Beard pointed out the daily stress of modern life as a possible cause of these symptoms. [27]

The British neurologist W.R. Gowers in 1904 coined the term "fibrositis" in an article on lumbago, which was referred to pain on touching by the fingertips of muscles hardened by inflammation of the fibrous tissue. Gowers also pointed out the presence of spontaneous pain and hypersensitivity to mechanical pressure, together with fatigue, sleep disorders and muscular symptoms. These symptoms seem to be worsen due to cold weather and physical efforts. He proposed manipulation, counterirritation, and cocaine injections as main treatments. [20]

In 1904, R. Stockman stated the pathological basics for the fibrous tissue inflammation theory of W.R. Gowers. Stockman proposed the existence of painful nodules, where hyperplasia was observed in inflammatory connective tissue. ${ }^{[28]}$ In subsequent publications, "fibrositis" became synonymous with a poorly defined painful disorder of rheumatic origin. [29]

In 1909, the famous physician W. Osler, explained that muscular rheumatism involves neuralgia of the sensory nerves of the muscles. Nevertheless, North American physicians didn't recognize fibrositis due to the uncertainty of physical signs, the inconsistent histologic changes, and the non-existence of specific laboratory tests. $\underline{[30]}$

In 1913, Llewellyn and Jones wrote a book, which included different medical conditions such as rheumatoid arthritis and gout, trying to catch all dimensions of fibrositis term. In addition, they divided fibrositis in articular, bursal, neural, muscular, gouty, infective, traumatic, or rheumatic. [31]

In 1927, Albee coined the term fibromiositis. Albee applied the term "myofibrositis" or "fibromiositis" and presumably ignored their different etiology, but introduced the possibility of including different pathologies with similar clinic manifestations. [32]

In 1936, C.H. Slocumb awoke an increasing interest in fibrositis. Slocumb stated that there was indirect evidence which confirmed the persistent integrity of the joint cavity in cases of fibrositis. While in periarticular fibrositis the disease was at the joint, not within the joint; in infectious arthritis there were fibrositis together with synovitis and other inflammatory diseases (i.e., chondritis and osteitis). [33]

In 1944, F. Elliot suggested that the pain experimented by fibromyalgia patients might involve the spinal cord and thalamus. [34] 
In 1945, Copeman developed the first controlled study showing that fibrositic nodules had a similar frequency in patients with fibromyalgia and in control subjects. [35] In this sense, the Stockman theory was refuted because biopsies performed on muscle tissues did not provide any evidence of inflammation. As a result, some authors explain that these initial uses of the term fibrositis in 1904 by Stockman, cannot be considered synonymous with fibromyalgia due to its association with inflammatory responses. [트]

In 1947, E.W. Boland based on the absence of physical findings corresponding to the symptomatology, modified the concept and reintroduced the term "psychogenic rheumatism", defined as musculoskeletal expression of functional disorders, stress states, or psychoneurosis. [18]

Some years later, a Boston physician called W. Graham (1953) used the term "fibrositis" to indicate a pain syndrome in the absence of any specific organic disease. In opinion of this author, the etiology may be infective, traumatic/occupational, or due to weather factors and psychologic disturbance. [37] This concept was accepted in the 1920s by European physicians. The term fibrositis, when assumed this meaning, might be considered as synonymous with fibromyalgia as we conceptualized it nowadays. Graham also reawaken the interest in fibromyalgia in the 1950s and 1960s by his contribution in a chapter on fibrositis in the worldwide known textbook of rheumatology: "Arthritis and allied conditions" (1949). [38]

In 1959, E.F. Rossenberg outlined a classification for "fibrositis".[39] Later, in 1989, C. Vitali stated the need for a classification of "primary fibromyalgia syndrome" or fibrositis. ${ }^{[40]}$

In 1968, E.F. Traut conceptualized "muscular fibrositis" or "non-articular rheumatism" as a syndrome defined by pain and stiffness present in trigger areas, in which the soft tissues of the neck, shoulder, elbow, carpal tunnel, palms (Dupuytren's contracture) and lower back area were included. To his mind, a cold or damp environment could be also implicated in the aggravation of this illness, which is similar to the Gower's idea in 1904. Traut also considered that the syndrome was practically limited to women, usually in the climacteric years. [41] This idea has been rejected with the subsequent evidence of fibromyalgia in women of different age, in men, and in pediatric population. Additionally, in the case of symptoms of muscular fibrositis in men, Traut explained they were more related to some recent, unexpected, unusual or persistent fatiguing effort. It is considered that Traut stated the first nearmodern description of fibromyalgia with systemic features. He also contributed to the study of fibromyalgia emphasizing the role of mind-body interactions in the pathogenesis of the disease. $\left.\underline{41}^{[}\right]$

In 1976, the term fibromyalgia was coined by P.K. Hench as a form of non-articular rheumatism based on the absence of specific inflammatory damage. ${ }^{[42]}$

In 1977, H.A. Smythe and H. Moldofsky continued the work of P.K. Hench and proposed the first measure for evaluating fibromyalgia in their work entitled "Two contributions to the understanding of the fibrositis syndrome". [43] This work influenced many fibromyalgia researchers in the 1970 s and 1980 s. It is considered that Smythe is the grandfather of modern fibromyalgia. It seems that he was the first to conceptualize fibromyalgia exclusively as a generalized pain syndrome, accompanied by fatigue, nonrestorative sleep, morning stiffness, emotional distress, and multiple tender points. [44] They proposed diagnostic criteria based on the core symptoms previously mentioned. [4ㄱ] Smythe also pointed out the presence of aggravating and relieving factors. ${ }^{[4]}$ At this regard, several authors have confirmed the existence of a series of factors that seem to modulate the symptoms of fibromyalgia. Among the factors that aggravate the symptoms are cold, stress, professional or domestic work overload,

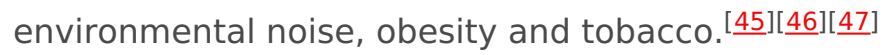

Furthermore, thanks to Smythe and Moldofsky, the role of sleep was properly recognized. Smythe offered a description of a real patient experience and provided sleep electroencephalogram (EEG) findings of absent stage-4 and near-absent stage-3 sleep, based on the unpublished work of his 
colleague Moldofsky. [44] These authors also hypothesized serotonin deficiency as a cause for such sleep anomalies in fibromyalgia. Moreover, they stated the possible role of distress in the beginning of fibromyalgia symptoms. They specifically suggested mechanical stress in the deep structures of the cervical and lumbosacral spine region as a factor for sustained reflex hyperalgesia. $\left.{ }^{[43}\right]$

Nevertheless, it was not until 1981 that the medical community accepted this disease under the term

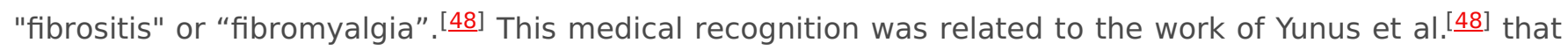
proposed the first formal set of criteria to diagnose primary fibromyalgia. Yunus conceptualized fibrositis or fibromyalgia as a form of nonarticular rheumatism in which predominant symptoms were chronic aches, pains, and stiffness in multiple areas of the musculoskeletal system, together with increased tenderness at specific tender or trigger points. ${ }^{[48]}$

Yunus also introduced the term secondary fibrositis for cases wherein a secondary condition (e.g., inflammation) were provoking the syndrome. The distinction between primary and secondary fibromyalgia disappeared sometime later. The criteria of Yunus et al. ${ }^{[48]}$ represented an important point in the study of fibromyalgia because it was the first time in which symptoms played a more central role in fibromyalgia diagnosis, which notably contributed to the understanding and treatment of this illness. In addition, Yunus had the credit for carrying out the first controlled study about the clinical characteristics of fibromyalgia, following a formal protocol and including 50 fibromyalgia patients and 50 matched healthy controls. $[\underline{48]}$

During the 1980 s, different authors suggested other formal and ad-hoc criteria sets. ${ }^{[49]}$ In 1985 , Yunus et al. performed the first description of juvenile fibromyalgia in a controlled study. $\underline{\text { [5] }]}$ In 1987, D.L. Goldenberg published a set of diagnostic criteria for fibromyalgia, distinguishing between mandatory and minor diagnostic criteria. ${ }^{[51]}$ In 1988, Vaeroy et al. ${ }^{[52]}$ developed the first report of elevated substance $P$ in cerebrospinal fluid of patients with fibromyalgia, being confirmed these results by Rusell in 1994. $[33]$ In 1989, J.I. Hudson proposed overlaps between fibromyalgia and related conditions as well as several psychiatric illnesses. ${ }^{[54]}$ However, sometime later these syndromes were proposed to be more connected to central sensitization rather than by affective mechanisms. [ㄷ5][ㅎ6]

In 1987, the American Medical Association accepted fibromyalgia as a real disease. Shortly thereafter and as a result of this recognition, the American College of Rheumatology (ACR) created a committee to establish the diagnostic criteria for this disorder. ${ }^{[57]}$

The first official diagnostic criteria were proposed in 1990 by the ACR and it was definitely decided to use the term fibromyalgia instead of fibrositis. In 1992, the World Health Organization (WHO) recognized fibromyalgia as a disease and it was classified within non-articular rheumatisms under code M.79.7 of the International Classification of Diseases (ICD). ${ }^{[57]}$ And since 1992, every May $12^{\text {th }}$, World Fibromyalgia and Chronic Fatigue Syndrome Day is celebrated. In 1994, fibromyalgia was also recognized by the International Association for the Study of Pain (IASP) and classified with the code $\times 33 \times 8 a$. $\underline{[57]}$

During the 1990s, there was an increase in fibromyalgia research. Some of the most relevant researches were the first demonstration of hypothalamic-pituitary-adrenal axis abnormalities in a well-designed study which showed exaggerated ACTH (adrenocorticotropic hormone) release with relative hyporesponsiveness, ${ }^{[58]}$ the first United States population study showing $2 \%$ prevalence of fibromyalgia, $\underline{[59]}$ the first study of brain imaging by SPECT (Single Photon Emission Computed Tomography) showing

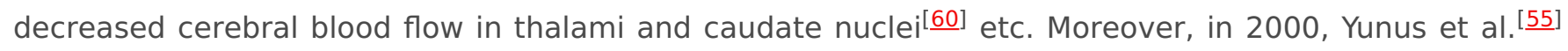
performed an important review of evidence for central sensitization in fibromyalgia and other related syndromes in which the term central sensitization syndromes was coined. One year later R. Staud performed a well-designed study showing temporal summation of pain in fibromyalgia. $\underline{[56]}$ Nowadays, the presence of central sensitization to pain and deficits in endogenous pain inhibitory mechanisms in fibromyalgia is one of the most well supported hypotheses regarding its pathophysiology. [61][드] 
In 2010, the ACR proposed a new version of the diagnostic criteria based exclusively on the use of two scales: the Widespread Pain Index (WPI) and the Symptom Severity (SS) Scale. In addition, other two subsequent diagnostic proposals were performed. [16] In 2011, Wolfe et al. revised and modified the 2010 ACR diagnostic criteria. These modifications were made to facilitate its use in epidemiological or community studies, but not for self-diagnosis in the clinical context. $\left.{ }^{63}\right]$ In 2016, ACR criteria were proposed to combine the 2010 and 2011 ACR criteria into a single set to overcome the previous limitations. $[\underline{64]}$

Definitely, fibromyalgia involves high personal, family and financial costs. Fibromyalgia provokes disability and dependence on the family to perform daily activities, which at the same time causes stress and discomfort in people who suffer from fibromyalgia and their relatives; as well as feelings of guilt and frustration in the patients which worsen their medical condition. In addition, many fibromyalgia patients are unable to go to work and this make their own and the family's economic situation worse. [ㄷ]

Moreover, fibromyalgia patients showed low Health Related Quality of Life levels, regardless of the

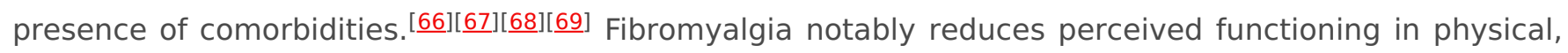
psychological, and social spheres, and has a negative impact on personal relationships, parenting, work,

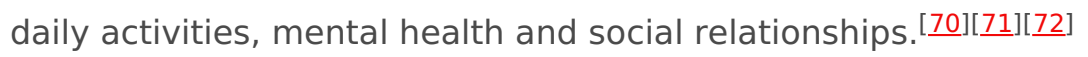

Regarding socio-economic costs, fibromyalgia implies high economic costs for the socio-health system, because of these patients go more to the medical office (both to general medicine and to different medical specialties) and need more prescriptions and medical tests (especially neuroimaging and laboratory tests) than the rest of the population. ${ }^{[65]}$ It is estimated that before obtaining the correct diagnosis, fibromyalgia patients have twice of visits to the general practitioner and twice of prescriptions compared to other disorders. $[\underline{73}]$

\section{References}

1. Pain IASP Taxonomy . International Association for the Study of Pain-IASP. Retrieved 2020-6-13

2. M. M. Veehof; Maarten-Jan Oskam; Karlein M.G. Schreurs; Ernst T. Bohlmeijer; Acceptance-based interventions for the treatment of chronic pain: A systematic review and meta-analysis. Pain 2011, 152, 533-542, 10.1016/j.pain.2010.11.002.

3. Ronald Melzack; Pain and the Neuromatrix in the Brain. Journal of Dental Education 2001, 65, 1378-1382, 10.1002/j.0022-0337.2001.65.12.tb03497.x.

4. Frederick Wolfe; Hugh A. Smythe; Muhammad B. Yunus; Robert Bennett; Claire Bombardier; N L. Goldenberg; Peter Tugwell; Stephen Campbell; Micha Abeles; Patricia Clark; et al.Adel G. FamStephen J. FarberJustus J. FiechtnerC. Michael FranklinRobert A. GatterDaniel HamatyJames LessardAlan S. LichtbrounAlfonse T. MasiGlenn A. McCainW. John ReynoldsThomas J. Romanol. Jon RussellRobert P. Sheon The american college of rheumatology 1990 criteria for the classification of fibromyalgia. Arthritis Care \& Research 1990, 33, 160-172, 10.1002/art.1780330203.

5. Sachin Srinivasan; Eamon Maloney; Brynn Wright; Michael Kennedy; K. James Kallail; Johannes J. Rasker; Winfried Häuser; Frederick Wolfe; The Problematic Nature of Fibromyalgia Diagnosis in the Community.. ACR Open Rheumatology 2019, 1, 43-51, 10.1002/acr2.1006.

6. Frederick Wolfe; Brian Walitt; Serge Perrot; Johannes J. Rasker; Winfried Häuser; Fibromyalgia diagnosis and biased assessment: Sex, prevalence and bias. PLOS ONE 2018, 13, e0203755, 10.1371/journal.pone.0203755.

7. Jennifer M. Glass; Denise C. Park; Meredith Minear; Leslie J. Crofford; Memory beliefs and function in fibromyalgia patients. Journal of Psychosomatic Research 2005, 58, 263-269, 10.1016/j.jpsychores.2004.09.004.

8. John McBeth; Matthew R. Mulvey; Fibromyalgia: mechanisms and potential impact of the ACR 2010 classification criteria. Nature Reviews Rheumatology 2012, 8, 108-116, 10.1038/nrrheum.2011.216.

9. Ricardo Campos; Maria Isabel Rodríguez Vázquez; Health-related quality of life in women with fibromyalgia: clinical and psychological factors associated. Clinical Rheumatology 2011, 31, 347-355, 10.1007/s10067-011-1870-7.

10. Carmen M. Galvez-Sánchez; Gustavo A. Reyes Del Paso; Stefan Duschek; Cognitive Impairments in Fibromyalgia Syndrome: Associations With Positive and Negative Affect, Alexithymia, Pain Catastrophizing and Self-Esteem. Frontiers in Psychology 2018, 9, 1-14, 10.3389/fpsyg.2018.00377.

11. Carmen M. Galvez-Sánchez; Cristina Muñoz Ladrón De Guevara; Casandra I. Montoro; María José Fernández-Serrano; Stefan Duschek; Gustavo A. Reyes Del Paso; Cognitive deficits in fibromyalgia syndrome are associated with pain 
responses to low intensity pressure stimulation. PLOS ONE 2018, 13, e0201488, 10.1371/journal.pone.0201488.

12. Fabienne Coury; Arnaud Rossat; Alexandre Tebib; Marie-Claude Letroublon; Anne Gagnard; Bruno Fantino; Jacques G. Tebib; Rheumatoid Arthritis and Fibromyalgia: A Frequent Unrelated Association Complicating Disease Management. The Journal of Rheumatology 2009, 36, 58-62, 10.3899/jrheum.080366.

13. Frederick Wolfe; Michelle Petri; Graciela S. Alarcón; John Goldman; Eliza F. Chakravarty; Robert S. Katz; Elizabeth W. Karlson; Kaleb Michaud; Fibromyalgia, systemic lupus erythematosus (SLE), and evaluation of SLE activity.. The Journal of Rheumatology 2009, 36, 82-8, 10.3899/jrheum.080212.

14. Valderilio Feijó Azevedo; Eduardo Dos Santos Paiva; Lúcio Ricardo Hiurko Felippe; Ranieri Amorim Moreira; Concomitância de fibromialgia em pacientes com espondilite anquilosante. Revista Brasileira de Reumatologia 2010, 50, 646-650, 10.1590/s0482-50042010000600005.

15. Marina De Tommaso; M Sardaro; C Serpino; F Costantini; F Vecchio; M Pia Prudenzano; P Lamberti; P. Livrea; Fibromyalgia Comorbidity in Primary Headaches. Cephalalgia 2009, 29, 453-464, 10.1111/j.14682982.2008.01754.x.

16. Frederick Wolfe; Daniel J. Clauw; Mary-Ann Fitzcharles; N L. Goldenberg; Robert S. Katz; Philip Mease; Anthony S. Russell; I. Jon Russell; John B. Winfield; Muhammad B. Yunus; et al. The American College of Rheumatology Preliminary Diagnostic Criteria for Fibromyalgia and Measurement of Symptom Severity. Arthritis Care \& Research 2010, 62, 600-610, 10.1002/acr.20140.

17. George Beard; Neurasthenia, or Nervous Exhaustion. New England Journal of Medicine 1869, 80, 217-221, 10.1056/nejm186904290801301.

18. E. W. Boland; Psychogenic Rheumatism: The Musculoskeletal Expression of Psychoneurosis. Annals of the Rheumatic Diseases 1947, 6, 195-203, 10.1136/ard.6.4.195.

19. Murray, G; An Address ON MYOFIBROSITIS AS A SIMULATOR OF OTHER MALADIES.. The Lancet 1929, 213, 113-116, 10.1016/s0140-6736(00)82431-9.

20. Gowers, W.R; The development of the concept of fibrositis.. Br Med J 1904, 1, 117-121.

21. Robert M. Bennett; Fibrositis: Misnomer for a Common Rheumatic Disorder. Western Journal of Medicine 1981, 134, 405-413.

22. E A Awad; Interstitial myofibrositis: hypothesis of the mechanism.. Archives of Physical Medicine and Rehabilitation 1973, 54, 449-453.

23. Baillou, G. Liber de Rheumatismo et pleuritide dorsali; Thevart MJ: Thevart MJ: Paris, France, 1642; pp. 25.

24. R. Manningham . Symptoms, Nature, Causes, and Cure of Low-grade Fever or Fever: Commonly Called Nervous or Hysterical Fever; Spirit Fever; Vapors, Hiccups, or Spleen; J. Robinson, Eds.; British Library: London: British Library, 1750; pp. 138.

25. Quirós Álvarez, Oscar J; Rodríguez, Liliana; Lezama, Ernesto; Quirós C, Jelsyka; Quirós C, Luzmarina; Fibromialgia y Ortodoncia. Actitud del Ortodoncista ante la enfermedad invisible. Acta odontol. venez 2002, 40 (2), $144-151$.

26. Froriep R. Ein beitrag zur pathologie und therapie des rheumatismus; Weimar: Weimar, Germany, $1843 ;$ pp. 292.

27. Beard, G.M. A Practical Treatise on Nervous Exhaustion (Neurasthenia); William Wood and Co: New York: William Wood and Co, 1880; pp. 272.

28. Ralph Stockman; The Causes, Pathology, and Treatment of Chronic Rheumatism. Edinburgh medical journal 1970, 15, 223-235.

29. Michael D. Reynolds; The Development of the Concept of Fibrositis. Journal Of The History Of Medicine And Allied Sciences 1983, 38, 5-35, 10.1093/jhmas/38.1.5.

30. Osler, W. The Principles and Practice of Medicine; D. Appleton and Company: New York: D. Appleton and Company, 1909; pp. 630.

31. Llewellyn, L.J, Jones, A.B. Fibrositis; William Heinemann: London: William Heinemann, 1913; pp. 100.

32. Albee, F; Myofasciitis: a pathological explanation of any apparently dissimilar conditions. Am J Surg 1927, 3, 523533.

33. C. H. Slocumb; Differential Diagnosis of Periarticular Fibrositis and Arthritis. Annals of the Rheumatic Diseases 1940, 2, 108-113, 10.1136/ard.2.2.108.

34. F. A. Elliott; Aspects of "Fibrositis". Annals of the Rheumatic Diseases 1944, 4, 22-25, 10.1136/ard.4.1.22.

35. W.S.C. Copeman; L.G.C. Pugh; EFFECTS OF ARTIFICIAL DEHYDRATION IN RHEUMATISM. The Lancet 1945, 246, 553556, 10.1016/s0140-6736(45)91272-4.

36. Vidal, L.F. Fibromialgia en la Práctica Diaria; MEGATRAZO S.A.C: Lima, Perú: MEGATRAZO S.A.C, $2015 ;$ pp. 566.

37. W Graham; The fibrosits syndrome.. Bull Rheum Dis 1953, 3, 33-4.

38. Graham. W. Fibrositis. In Arthritis and Allied Conditions; Hollander JL., Eds., Eds.; Lea \& Febiger : Philadelphia: Lea \& Febiger, 1949; pp. 622-647.

39. Edward F. Rosenberg; Classification and Management of Fibrositis. Medical Clinics of North America 1958, 42, 1613$1627,10.1016 / \mathrm{s} 0025-7125(16) 34208-0$. 
40. C Vitali; A Tavoni; B Rossi; E Bibolotti; C Giannini; L Puzzuoli; R Cacialli; G Pasero; Evidence of neuromuscular hyperexcitability features in patients with primary fibromyalgia.. Clinical and experimental rheumatology 1989, 7 , 385-390.

41. Traut, E.F; Fibrositis. J Am Geriatr Soc 1968, 16, 531-538.

42. Hench, P.K; Nonarticular rheumatism, 22nd rheumatism review: review of the American and English literature for the years 1973 and 1974. Arthritis Rheumatol 1976, 19, 1081-1089.

43. H A Smythe; H Moldofsky; Two contributions to understanding of the "fibrositis" syndrome.. Bulletin on the rheumatic diseases 1977, 28, 928-931.

44. Smythe, H. Nonarticular rheumatism and psychogenic musculoskeletal syndromes. In Arthritis and Allied Conditions; McCarty DJ, Eds.; Lea \& Febiger: Philadelphia: Lea \& Febiger, 1972; pp. 881-889.

45. Virginia A. Aparicio; Francisco B. Ortega; Jose Heredia-Jimenez; Ana Carbonell-Baeza; Manuel Delgado-Fernández; Análisis de la composición corporal en mujeres con fibromialgia. Reumatología Clínica 2011, 7, 7-12, 10.1016/j.reuma.2010.05.006.

46. Dennis W. Boulware; Lynne D. Schmid; Melanie Baron; The fibromyalgia syndrome. Postgraduate Medicine 1990, 87, 211-214, 10.1080/00325481.1990.11704567.

47. Ömer Nuri Pamuk; Salim Dönmez; Necati Çakır; Necatı Çakir; The frequency of smoking in fibromyalgia patients and its association with symptoms. Rheumatology International 2009, 29, 1311-1314, 10.1007/s00296-009-0851-5.

48. Yunus, M, Masi, A.T, Calabro, J.J, et al; Primary fibromyalgia (fibrositis): clinical study of 50 patients with matched normal controls. Semin Arthritis Rheu 1981, 11, 151-171.

49. Frederick Wolfe; Winfried Häuser; Fibromyalgia diagnosis and diagnostic criteria. Annals of Medicine 2011, 43, 495502, 10.3109/07853890.2011.595734.

50. Muhammad B. Yunus; Alfonse T. Masi; Juvenile primary fibromyalgia syndrome. A clinical study of thirty-three patients and matched normal controls. Arthritis Care \& Research 1985, 28, 138-145, 10.1002/art.1780280205.

51. N L. Goldenberg; Fibromyalgia Syndrome. JAMA 1987, 257, 2782, 10.1001/jama.1987.03390200122026.

52. Henning Vaerøy; Robert Helle; Øystein Førre; Erik Kåss; Lars Terenius; Elevated CSF levels of substance P and high incidence of Raynaud phenomenon in patients with fibromyalgia: new features for diagnosis. Pain 1988, 32, 21-26, 10.1016/0304-3959(88)90019-x.

53. I. Jon Russell; Malcolm D. Orr; Bruce Littman; Gilbert A. Vipraio; David Alboukrek; Joel E. Michalek; Yolanda Lopez; Fane Mackillip; Elevated cerebrospinal fluid levels of substance $\mathrm{p}$ in patients with the fibromyalgia syndrome. Arthritis Care \& Research 1994, 37, 1593-1601, 10.1002/art.1780371106.

54. J I Hudson; H G Pope; Fibromyalgia and psychopathology: is fibromyalgia a form of "affective spectrum disorder"?. The Journal of Rheumatology Supplement 1989, 19, 15-22.

55. Yunus, M.B; Central sensitivity syndromes: a unified concept for fibromyalgia and other similar maladies. J Indian Rheumatism Assoc 2000, 8, 27-33.

56. Roland Staud; C.J. Vierck; Richard L. Cannon; Andre P. Mauderli; Donald Price; Abnormal sensitization and temporal summation of second pain (wind-up) in patients with fibromyalgia syndrome. Pain 2001, 91, 165-175, 10.1016/s0304-3959(00)00432-2.

57. Rafael Belenguer; Manuel Ramos-Casals; Antoni Sisó; Javier Rivera; Clasificación de la fibromialgia. Revisión sistemática de la literatura. Reumatología Clínica 2009, 5, 55-62, 10.1016/j.reuma.2008.07.001.

58. E N Griep; J W Boersma; E R De Kloet; Altered reactivity of the hypothalamic-pituitary-adrenal axis in the primary fibromyalgia syndrome.. The Journal of Rheumatology 1993, 20, 469-474.

59. F Wolfe; K Ross; J Anderson; I J Russell; L Hebert; The prevalence and characteristics of fibromyalgia in the general population.. Arthritis Care \& Research 1995, 38, 19-28.

60. J M Mountz; L A Bradley; J G Modell; R W Alexander; M Triana-Alexander; L A Aaron; K E Stewart; G S Alarcón; Fibromyalgia in women. Abnormalities of regional cerebral blood flow in the thalamus and the caudate nucleus are associated with low pain threshold levels.. Arthritis Care \& Research 1995, 38, 926-938.

61. Goubert D, Danneels L, Graven-Nielsen T, et al; Differences in pain processing between patients with chronic low back pain, recurrent low back pain, and fibromyalgia. Pain Physician 2017, 20, 307-318.

62. Jo Nijs; Mira Meeus; Jessica Van Oosterwijck; Nathalie Roussel; Margot De Kooning; Kelly Ickmans; Milica Matic; Treatment of central sensitization in patients with 'unexplained' chronic pain: what options do we have?. Expert Opinion on Pharmacotherapy 2011, 12, 1087-1098, 10.1517/14656566.2011.547475.

63. Frederick Wolfe; Daniel Clauw; Mary-Ann Fitzcharles; Don L. Goldenberg; Winfried Häuser; Robert S. Katz; Philip Mease; Anthony S. Russell; I. Jon Russell; John B. Winfield; et al. Fibromyalgia Criteria and Severity Scales for Clinical and Epidemiological Studies: A Modification of the ACR Preliminary Diagnostic Criteria for Fibromyalgia. The Journal of Rheumatology 2011, 38, 1113-1122, 10.3899/jrheum.100594.

64. Frederick Wolfe; Daniel J. Clauw; Mary-Ann Fitzcharles; N L. Goldenberg; Winfried Häuser; Robert L. Katz; Philip Mease; Anthony S. Russell; Irwin Jon Russell; Brian Walitt; et al. 2016 Revisions to the 2010/2011 fibromyalgia 
diagnostic criteria. Seminars in Arthritis and Rheumatism 2016, 46, 319-329, 10.1016/j.semarthrit.2016.08.012.

65. Jason W. Busse; Shanil Ebrahim; Gaelan Connell; Eric A Coomes; Paul Bruno; Keshena Malik; David Torrance; Trung Ngo; Karin Kirmayr; Daniel Avrahami; et al.John J. RivaPeter A A StruijsDavid BrunarskiStephen J. BurnieFrances Leblanclvan SteenstraQuenby MahoodKristian ThorlundVictor M. MontoriVishalini SivarajahPaul E AlexanderMilosz JankowskiWiktoria LeśniakMarkus FaulhaberMalgorzata M BalaStefan SchandelmaierGordon H. Guyatt Systematic review and network meta-analysis of interventions for fibromyalgia: a protocol. Systematic Reviews 2013, 2, 18-18, 10.1186/2046-4053-2-18.

66. Serge Perrot; Eric Vicaut; Dominique Servant; Philippe Ravaud; Prevalence of fibromyalgia in France: a multi-step study research combining national screening and clinical confirmation: The DEFI study (Determination of Epidemiology of Flbromyalgia). BMC Musculoskeletal Disorders 2011, 12, 224-224, 10.1186/1471-2474-12-224.

67. Andréll, P., Schultz, T., Mannerkorpi, K., Nordeman, L., Börjesson, M., y Mannheimer, C; Health-related quality of life in fibromyalgia and refractory angina pectoris: A comparison between two chronic non-malignant pain disorders. Journal of Rehabilitation Medicine 2014, 46, 341-347, 10.2340/16501977-1279.

68. Jeong-Won Lee; Kyung-Eun Lee; Dong-Jin Park; Seong-Ho Kim; Seong-Su Nah; Ji Hyun Lee; Seong-Kyu Kim; Yeon-Ah Lee; Seung-Jae Hong; Hyun-Sook Kim; et al.Hye-Soon LeeHyoun Ah KimChung-Il JoungSang-Hyon KimShin-Seok Lee Determinants of quality of life in patients with fibromyalgia: A structural equation modeling approach. PLOS ONE 2017, 12, e0171186, 10.1371/journal.pone.0171186.

69. Carmen M. Galvez-Sánchez; Casandra I. Montoro; Stefan Duschek; Gustavo A. Reyes Del Paso; Depression and traitanxiety mediate the influence of clinical pain on health-related quality of life in fibromyalgia. Journal of Affective Disorders 2020, 265, 486-495, 10.1016/j.jad.2020.01.129.

70. William B. Karper; Effects of exercise, patient education, and resource support on women with fibromyalgia: An extended long-term study. Journal of Women \& Aging 2016, 28, 555-562, 10.1080/08952841.2016.1223954.

71. Rodrigo Pegado De Abreu Freitas; Sandra Cristina De Andrade; Maria Helena Constantino Spyrides; Maria Thereza Albuquerque Barbosa Cabral Micussi; Maria B C Sousa; Impacts of social support on symptoms in Brazilian women with fibromyalgia. Revista Brasileira de Reumatologia (English Edition) 2017, 57, 197-203, 10.1016/j.rbre.2016.07.001.

72. Carmen M. Galvez-Sánchez; Casandra I. Montoro; Stefan Duschek; Gustavo A. Reyes Del Paso; Pain catastrophizing mediates the negative influence of pain and trait-anxiety on health-related quality of life in fibromyalgia.. Qual Life Res 2020, published online ahead of print, 1-11, 10.1007/s11136-020-02457-x.

73. Gwenda Hughes; Carlos Martinez; Eric Myon; Charles Taieb; Simon Wessely; The impact of a diagnosis of fibromyalgia on health care resource use by primary care patients in the UK: An observational study based on clinical practice. Arthritis Care \& Research 2005, 54, 177-183, 10.1002/art.21545.

\section{Keywords}

Fibromyalgia; Chronic Pain; Fibrositis

(c) 2020 by the author(s). Distribute under a Creative Commans CC BY license 